\title{
Introducing Troglodyte Architecture at Chabahar City in South-east of Iran
}

\author{
Hossein Sarhaddi-Dadian ${ }^{1,2}$, Zohre Oveisi-Keikha ${ }^{3}$, Vahid Purzarghan ${ }^{4}$ \\ ${ }^{1}$ Faculty of Art and Architecture, Department of Archaeology, University of Zabol, Zabol, Iran \\ ${ }^{2}$ Arcaeological Research Center, University of Zabol, Zabol, Iran \\ ${ }^{3}$ Faculty of Art and Architecture, Department of Architecture, University of Zabol, Zabol, Iran \\ ${ }^{4}$ Faculty of Art and Architecture, Department of Restoration, University of Zabol, Zabol, Iran
}

\section{Email address:}

h.Sarhaddi@uoz.ac.ir (H. Sarhaddi-Dadian)

\section{To cite this article:}

Hossein Sarhaddi-Dadian, Zohre Oveisi-Keikha, Vahid Purzarghan. Introducing Troglodyte Architecture at Chabahar City in South-east of Iran. International Journal of Archaeology. Vol. 5, No. 1, 2017, pp. 1-5. doi: 10.11648/j.ija.20170501.11

Received: January 22, 2017; Accepted: February 3, 2017; Published: March 1, 2017

\begin{abstract}
The present article is an attempt to investigate Tis caves in Chabahar city for the first time. Chabahar is located in the on the southern edge of Sistan-Baluchestan province near the Gulf of Oman. Historically, this region is one of the most important centers of human settlement and serves as a bridge connecting South East Iran to other civilizations, including the southern Persian Gulf and Oman Sea. The rich culture of this region served as an incentive for addressing various aspects of the history of this region. In this study, the authors study 3 caves carved into the hillside of Shahnaz. These caves are located about 25 meters above the road on the north side of the Tis village and are investigated from two perspectives. A) The structure of triple caves b) the application of these caves according to cultural materials and other cultural works available around them. Two out of the three caves in this region (the central and eastern caves) are accessible and the western cave is blocked due to landslide and can't currently be investigated. The Central cave has plastered walls and the graves inside this gave show that it was used for burials. The Western Cave that has plastered walls as well, includes no grave, and was probably more of a pilgrimage. However, according to the anthropological studies and considering that the western cave overlooks the sea and includes some graves, this cave has been more of a holy place that is carved into the hillside by the people and belongs to the late Islamic period. For the final decision about the areas we need to do more archaeological excavation in these caves.
\end{abstract}

Keywords: Troglodyte Architecture, Chabahar, Tis, South-East, Iran

\section{Introduction}

Southeast of Iran since the Bronze Age until now has had an effective and salient role in the creation of human culture and civilization in Iran $[1,2,3,4,5,6]$. The ancient village of Tis that neighbors the city of Chabahar, Sistan and Baluchestan, Iran is located in a mountain area $5.5 \mathrm{~km}$ northwest of Chabahar near the Gulf of Oman (see fig. 1a). The ancient history of this port dates back to ancient times and this village is home to many monuments. The Tis is one of the most important Iranian ports in the Arabian Sea and was formerly known as Tìz. At the old times, goods were usually transported from East Asia and India to this Port and then to different parts of the Middle East, Central Asia and Caucasus. Tis was also an important port in the early Islamic centuries and Moqadasi, the historian of the fourth century $\mathrm{AD}$, also spoke of the port's prosperity [7].

Port 'Tis," that is also referred to as "Tiz"and"Tīz Post" in different resources, serves as the border between Pars Sea and the Indian Ocean, and has long been an ancient link between the merchants and mariners who traveled from the Persian Gulf to the Indian Ocean coast and vice versa. According to the geographers of the first Islamic centuries, this port was the most important commercial harbor in the Arabian Sea from the Strait of Hormuz to Bandar "Dible" at the Indus River's mouth. Lowry River passes through the village and the Chabahar Bay is located in the West of this river. This village is surrounded by several heights such as the Shahbaz, Pilband and Lowry mountains. The village's climate is hot and dry. Tis is a major center of needlework 
that is mainly practiced by women. The village has a fortress known as the Portuguese fortress that is historically and architecturally remarkable; however, today this fortress is just a ruin. Tis is $6-11$ meters above sea level and the Lowry seasonal river passes through its center. The village is located at the mouth of Chabahar Bay and its center is about 400 to 600 meters away from the beach. There are no considerable heights in this village, except for Pilband heights with a maximum height of 180 meters in the north side and the Shabazband heights with a maximum height of 40 meters on the north side. Tis residents are Baloch and their main occupation is fishing. Animal husbandry and agriculture are also practiced in this village on a small scale [8].

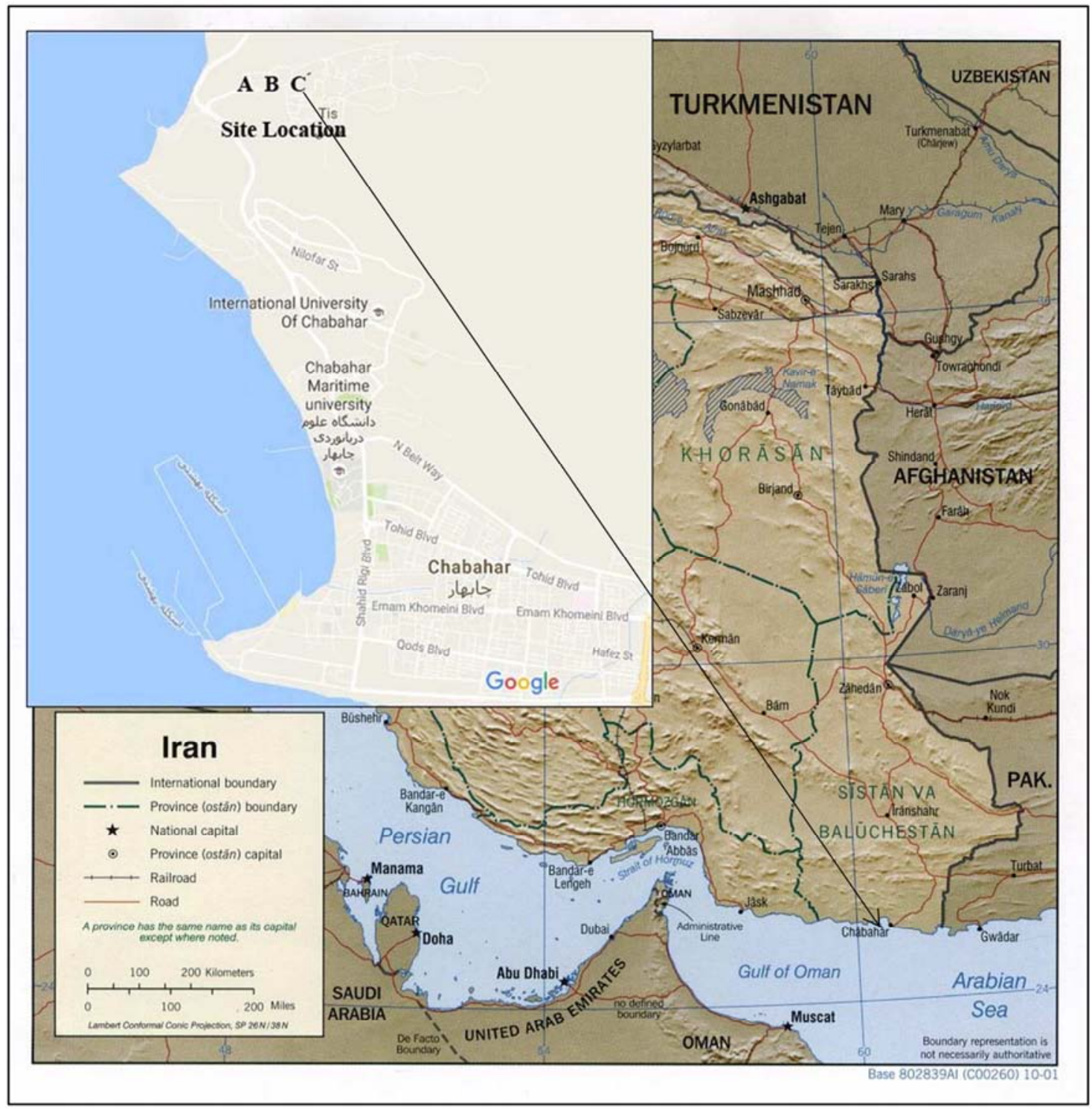

Figure 1a. Location of the site in South East of Iran.

\section{Archaeological Research Background}

The first scientific study on Chabahar was conducted by Aurel Stein, a Hungarian-born English archeologist. He explored the Damb kooh area belonging to the Parthian period and also visited the Tis village; he has also referred to some ancient monuments of this port in his reports. From 1931 to 1933 he investigated vast areas of Iran including Sistan and Baluchestan, Kerman, Hormozgan, Bushehr, and did scientific excavations in some areas. The reports of these studies were published in form of a book in 1937 [9]. In a field course for associate students of archaeology at the University of Sistan and Baluchestan, Dr. Ali Asghar Mirfatah conducted a speculation program in the Portuguese fortress located in Tis [10]. Other studies conducted in this area include: the study conducted by Hossein Moradi in Zarabad Konarak [11], investigation of Konarak County as part of Chabahar City [12]. The latest archaeological study conducted in this region was an archaeological study of Chabahar city led by Dr. Shirazi, from University of Sistan and Baluchestan during the spring of 1389 [13], which aimed to prepare the archeological map of Sistan and Baluchestan Province. 


\section{Troglodyte Architecture in Iran and Its Applications}

Stein was the first people to study and research on Iran's rocky architecture [9]; and after him some of scholar such as Vandenberg [14]; Arevik Ball [15] introduced some Troglodyte Architecture. These figures introduced and studied the rock architectures. After that, Iranian archaeologists conducted sporadic. And sometimes specialized researcher who studied on these structures. Lack of acceptable findings and difficult access to them are among the problems encountered during investigation of this particular type of architecture and determination of their chronology. These problems lead to an insufficient recognition of these structures, and consequently to speculations that are unfounded in most cases [16].

Rock Architectures are indicative of the struggle between man and nature and employment of natural rocks. In typical architecture, the main body of a structure is formed using building materials, plaster, lime and clay, whereas in the rock architecture the internal space is formed within a piece of rock, and the rock provides a strong and robust covering around this space; in some cases rocky structures use as a residential area such as Karaftu cave [17]. In some instances Troglodyte Architecture use as a carving of religious architecture such as Mithraism temples [18], and sometimes seen as grave temple like Palmyra at Kharg Island in South of Iran [19].

\section{Introduced of the Three Troglodyte Architecture in Chabahar}

At the foot of Mount Shahnaz, in the historic village of Tis and about 22-25 $\mathrm{m}$ above the ground, two artificial caves and a natural cave are developed. According to the ethnographic studies conducted in form of in-site interviews with indigenous people, these caves are called "Banmasity". In the Baluchi language 'ban' means holy man or monk and 'masity' means temple or place of worship and it is believed that the name of these caves means holy man temple. In order to establish order in this study the authors divided the caves into 3 categories from left to right: A, B, C. All three caves are located on the southern slopes of the mountain and are almost connected to the village. Since this mountain has a sedimentary structural and its constituent elements are weaker than other mountains' constituent elements, and are always subject to erosion by climatic factors such as monsoon rains, part of the mountain where caves are located has been destroyed to the extent that it is now hardly possible to access cave A, and prevention of further destructions require special attentions on the part of authorities (Fig. 1b). The cuts and carvings on the exterior and interior surface of caves A, B can be clearly observed which indicate human intervention in their construction (Fig. 2). Cave $\mathrm{C}$ that is located at a distance of approximately 60 meters east; is a natural cave with architecture evidences that will be discussed later.

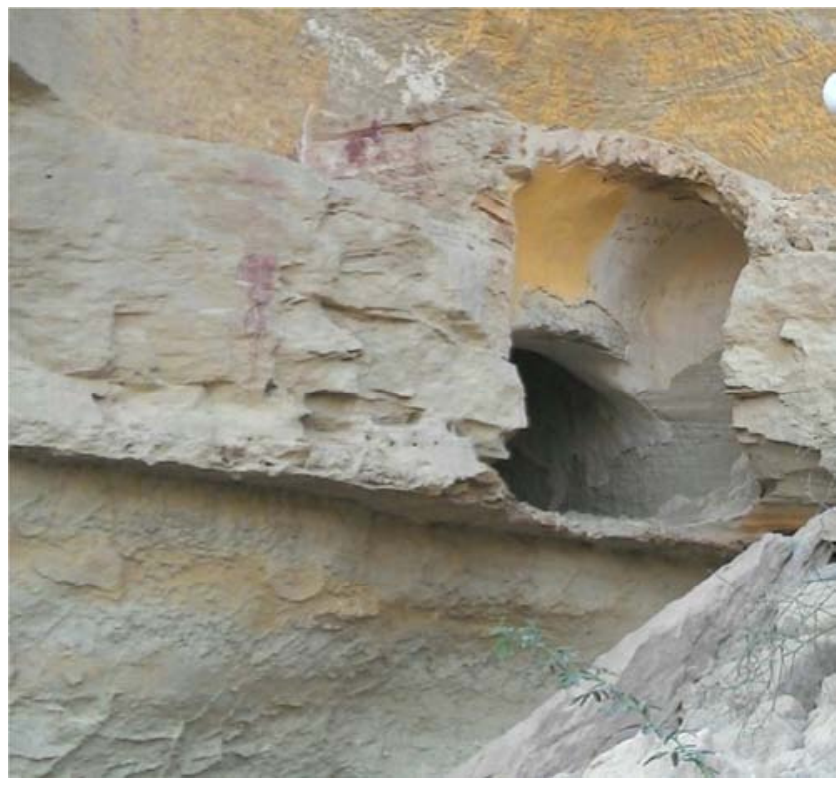

Figure 1b. Cave No, A (Sarhaddi 2015).

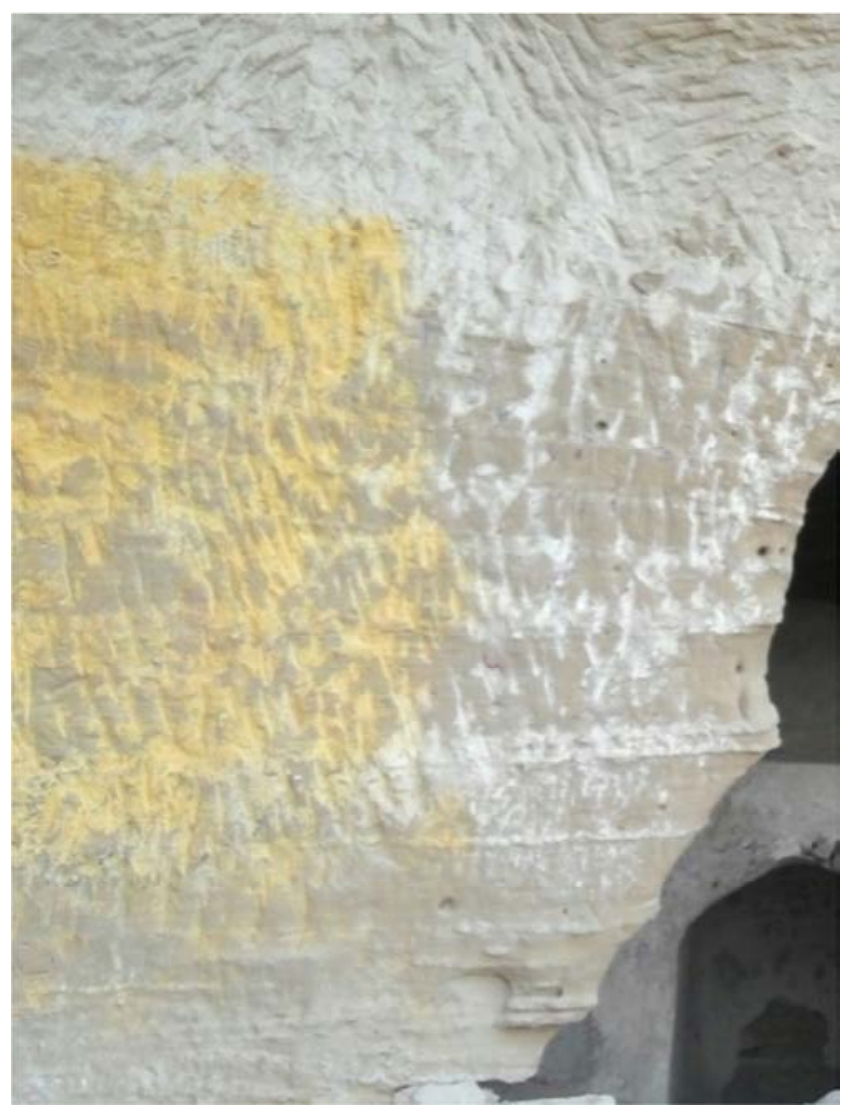

Figure 2. Indicate Human Intervention in their Construction (Sarhaddi 2015).

\section{Manmade Cave A}

This cave is the first and most Western cave among the three caves in Tis. Currently this cave is inaccessible due to landslides. Its height is around 22 meters above the ground 
and is architecturally, a combination of natural architecture and brick structure. In other words, in the entrance of the cave, there is a small chamber made of brick, mud and plaster. This chamber is more of a protection room for the main space in the heart of this mountain. The ceiling of this Protective structure is in the form of a cradle which forms parts of the terrace platform in cave B. currently, part of the brick structure has collapsed (Figure 3). The entrance chamber and the inner walls of the cave are covered with plaster, however, a vast area of the plaster has collapsed or turned yellow due to high humidity. The cave entrance about 220 centimeters high and $20.1 \mathrm{~cm}$ wide. The internal area of the cave has a Cone-shaped structure with a diameter of 2 meters which grows narrower at higher heights finally leading to a sugar colt-like roof.

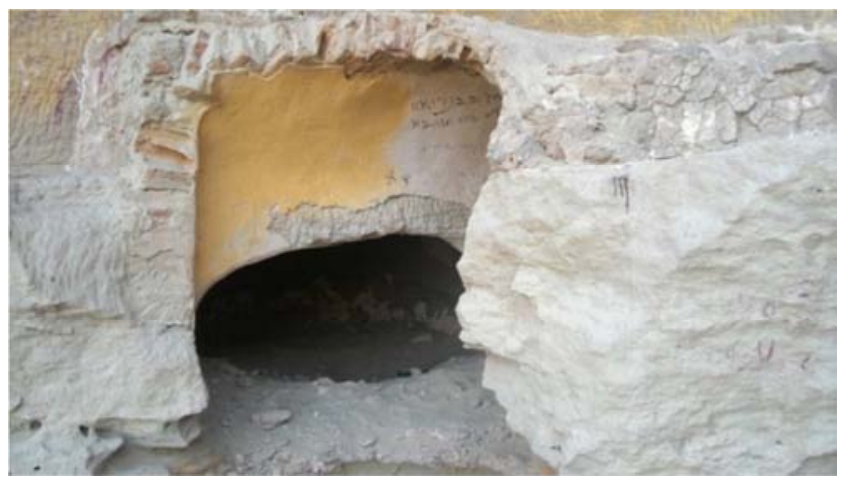

Figure 3. Cave No, A (Sarhaddi 2015).

\section{The Manmade Cave B}

Cave $\mathrm{B}$ is located about 10 meters to the right of cave A (Figure 4) and is structurally similar to cave A. this manmade architecture is 25 meters above the surrounding lands. Currently this cave is accessible only through a staircase constructed by the Chabahr free zone Organization, and has greatly facilitated our access to the cave. The cave's entrance is $180 \mathrm{~cm}$ high and 1.30 meters wide, but due to excessive erosion, the lower part of the entrance is $1.70 \mathrm{~cm}$ wide, and has formed a deranged and irregular entrance. As for internal structure, this cave is similar to cave A (cone-shaped structure) which grows narrower at the higher heights finally leading to a sugar colt-like roof. The cave is 3.5 meters high. The internal surface of the cave coated with white plaster, but the plaster coating has largely collapsed due to erosion. a small rectangular-shaped structure with a dome is constructed almost at the center of this cave, this structure is made of brick and mud. The rectangular structure's size is $2 \mathrm{x}$ 1 meter and has a cone-shaped roof with an entrance of $60 \mathrm{x}$ $40 \mathrm{~cm}$ built on the south side of the cave. This dome is structurally irregular and according to local residents, it is a grave, but there is no sign of any grave inside the cave. And this structure has probably been more of a holy shrine (Figure 5). One of the interesting points about this cave is the red signs and symptoms on plaster or mud. These signs and symbols need linguistic investigations. A 10 meter long and 15 meter wide terrace made of stone and plaster is located at the entrance of this cave, however this terrace is largely destroyed due to severe landslide.

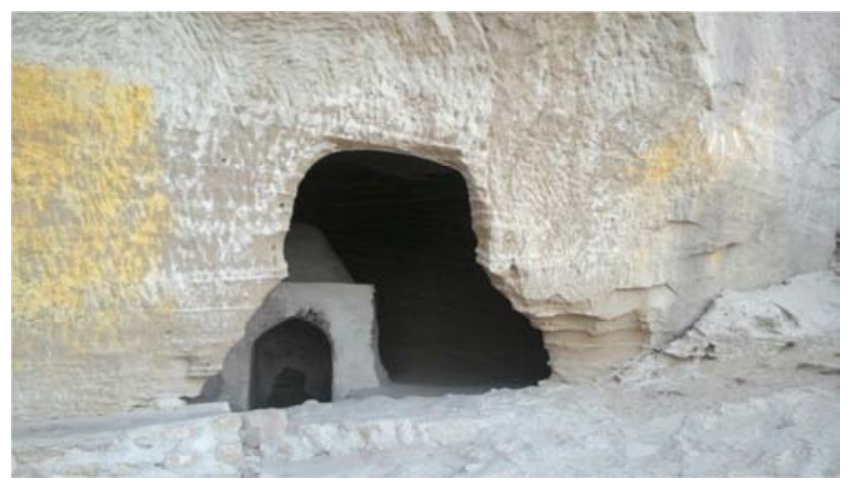

Figure 4. Cave No, A (Sarhaddi 2015).

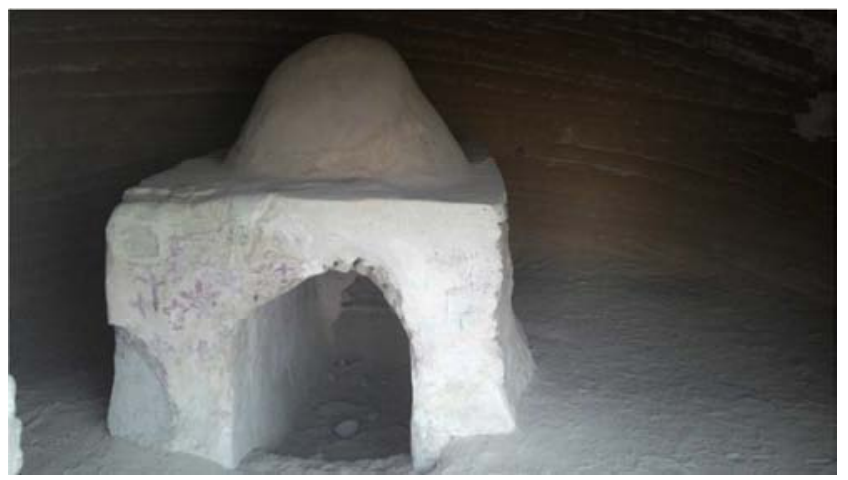

Figure 5. Cave No, A, a Holy Shrine (Sarhaddi 2015).

\section{Natural Cave $\mathbf{C}$}

The third cave (C) is located 50 meters to the left of cave (B) and its entrance arc is about 20 meters long. This cave is larger than the other two caves and its entrance is $1.30 \mathrm{~m}$ high and 30 meters long. The diameter of the cave's entrance is $15 \mathrm{~m}$ (Figure 6). There is no evidence of human habitation in the cave but the investigations carried out by the authors show that the clay and plaster used in this cave are indicative of the fact that this cave had probably included buildings and facilities and had been used by humans, however the internal parts of the cave are buried under the debris of landslide and require accurate archaeological excavations (Figure 7).

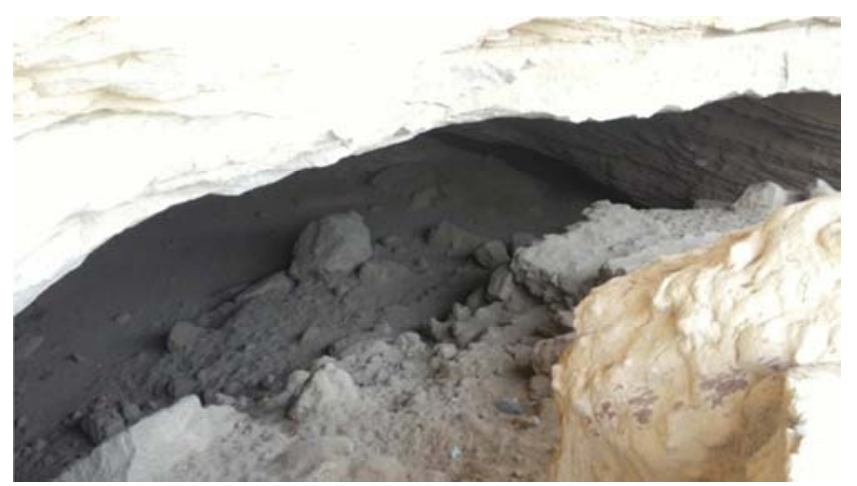

Figure 6. Cave No, C (Sarhaddi 2015). 


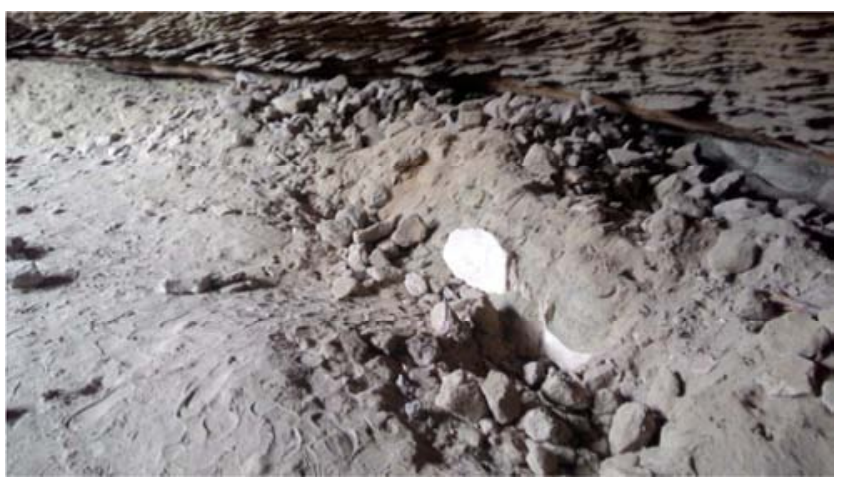

Figure 7. The Evidence of Wall in Cave No, C (Sarhaddi 2015).

\section{Conclusion}

At the foot of Shahnaz Mountain, about 20 - 25 meters above ground level, there are 3 caves (two artificial and manmade caves and one natural cave) which are of great importance to the inhabitants of this region. These caves are known as Banmasity, and In the Baluchi language 'ban' means holy man or monk and 'Masity' means temple or place of worship and it is believed that the name of these caves means holy man temple. In Cave B, there are the remains of a cuboid tomb whose dome is about $50 \mathrm{~cm}$ high. There are red and purple Gujarati script inscribed on this tomb, but since no linguistic studies have been done on them; no certain comment can be mad about their nature. in addition to this artificial cave with a tomb inside it, there are two other caves ( $B$ and $C$ ) in this mountain, Cave $C$ is located on the left of cave $\mathrm{B}$, and there are no evidences of human habitation in this cave. However, there are some evidences that prove the existence of walls inside this cave that are now buried under the rubble of roof collapse. Cave A is located to the left side of cave $\mathrm{B}$ and is completely artificial. Its height is lower than the other two caves. The signs of carvings on the walls of caves A and B are quite clear. These carvings are indicative of human involvement in their construction. The carvings and the tomb within these caves probably show that the three caves used to be a unified whole with a broad platform constructed before them for religious ceremonies or other formalities. It can also be concluded that, these caves probably served as a shrine in old days. However, any definite conclusion in this regard requires further studies and archaeological excavations.

\section{References}

[1] Moradi, H., Sarhaddi-Dadian, H. S., Soltani, M., Rahman, N. H. S. N. A., \& Chang, B.-o. (2013). "Study and Typological Comparison of Petroglyphs in the Marzbanik Valley, Baluchestan, Iran”. Time and Mind, 6, 331-349.

[2] Moradi, Hossein, Hossein Sarhaddi-Dadian and Nik Hassan Shuhami Nik Abdul Rahman, "Development and Decline of the Bampur Valley, Based on the New Archaeological evidences in Prehistoric period", Iranian Studies, Vol 47 (2) 2014.
[3] Sarhaddi-Dadian, H. Moradi, H. Soltani, M. (2015a). Preliminary Study of Rock Art at Negaran Valley in Baluchistan, Iran. Rock Art Research 32, no 2: 240-243.

[4] Sarhaddi-Dadian, H. Zuliskandar Ramli, Nik Hassan Shuhami Nik Abdul Rahmanand Reza Mehrafarin. (2015b). X-Ray Diffraction and X-Ray Fluorescence Analysis of Pottery Shards from New Archaeological Survey in South Region of Sistan, Mediterranean, Archaeology and Archaeometry, Vol 15 (3) 45-56.

[5] Sheikhakbari Samira, Hossein Sarhaddi-Dadian, Saeed Amirhajloo, Ali Daneshi (2015). Comparative Study of Pottery Industry in Zeh-Klout Historical Period in RoudbarKerman with its Neighboring Cultures Based on the New Archaeological Evidences. International Journal of Archaeology. Vol 3 (2): 22-32.

[6] Bosworth, C Edmund. (2000). "Sistan and its local histories." Iranian Studies no. 33 (1-2): 31-43.

[7] Sajjaddi, S. M. S. (1995), Archaeology and Baluchestan History. Tehran Iran's Culture Heritage Organization. (In Persian).

[8] Safarzai, A؛ Sepahi, A. (2012), history of trade and navigation at the port of Tis in Chabahar, Avalin Hamayeshe Tosey Savahele Makran va Eghtedar Jomhuri Eslami Iran, Chbahar, Iran.

[9] Stein, A. (1937), an Archaeological Tour in the Ancient Persis. Iraq. Vol. 3.

[10] Mirfattah, A. A. (1997), Report of archaeological Excavation in Tis Castel. Unpubl. Report, Cultural Heritage Organization.

[11] Moradi, H. (2008), Report of archaeological survey in Zarabad County. Unpubl. Report, Cultural Heritage Organization, Handicrafts and Tourism of Sistan and Baluchistan Province.

[12] Ali-Talesh, B. (2009), Report of archaeological survey in Konarak County. Unpubl. Report, Cultural Heritage Organization, Handicrafts and Tourism of Sistan and Baluchistan Province.

[13] Shirazi, R. (2010), Report of archaeological survey in Chabahar County. Unpubl. Report, Cultural Heritage Organization, Handicrafts and Tourism of Sistan and Baluchistan Province.

[14] Vandenberg, L. (1995), "Archaeology of Ancient Iran." Tehran University Press, Iran.

[15] Ball, W. (1986), some rock-cut monuments in southern Iran. IRAN. Vol. XXIV.] The British institute of Persian studies. p. 116-95.

[16] Rezvani, A. (2008), Kandovan (Showing of human adaptation with nature), Journal of Geography growth.

[17] Hamzelu, M؟ Mireskandari, M. (2002), Castel and Karaftoo Cave, Asar Vol (33-34): 278-304.

[18] Shenkar, Michael. (2007), "Temple architecture in the Iranian world before the Macedonian conquest." Iran and the Caucasus 11, no. 2: 169-194.

[19] Sarfaraz, A. A. (1975), Ancient Guide of Khark Island, National Organization for the protection of antiquities, Tehran, Iran. 